Battakhov P.P. ${ }^{\odot}$

Candidate of Law Sciences, senior research associate of the sector of enterprise and corporate law of Institute of state and law of the Russian Academy of Sciences (IGP RAS)

\title{
PECULIARITIES OF LEGAL REGULATION OF ENTREPRENEURIAL ACTIVITY OF SMALL PEOPLES OF THE NORTH
}

\begin{abstract}
The study of this work is aimed at defining the concept of «indigenous peoples of the North, Siberia and the Far East». In view of the proposed use of the new definition, it is advisable to exclude the concept of «small indigenous peoples of the North, Siberia and the Far East» from legislative acts. Special attention was paid to the legal regulation of the entrepreneurial relations of the state and economic entities that conduct their activities in the Far North. A proposal was put forward to develop entrepreneurial activity in this region in eight areas, in the Federal Law "On the Development of Small and Medium-Sized Businesses in the Russian Federation» amended to improve entrepreneurial activity and employment in economic entities of First Nations living in the Far East, the North and Siberia.
\end{abstract}

Keywords: indigenous peoples, the Far North, territory, small peoples, living conditions, entrepreneurial activity, legal regulation, legislation.

The indigenous small peoples of the North, Siberia and the Far East were able to ensure the preservation of land in large numbers. At the moment, there are about 40 such peoples in Russia who live mainly in such territories of the Russian Federation: the Republic of Sakha (Yakutia), the Chukotka Autonomous Okrug, the Khanty-Mansi Autonomous Okrug, Krasnoyarsk Territory. In the current legislation, it is the indigenous peoples of the North, Siberia and the Far East that are included in this list [1].

Despite extreme conditions, small indigenous peoples were able to survive. These are real old-timers among all peoples who have managed to ensure the safety of their culture, life, and lifestyle. Despite the difficult living conditions, they are actively developing. In winter, the temperature can drop below $60^{\circ} \mathrm{C}$, and in summer it is up to $+20^{\circ} \mathrm{C}$. In the laws in force, these indigenous peoples, who live in the North, Siberia and the Far East, have been generalized under one name, "the ancestral peoples of the North" [2].

Very often you can hear that all the peoples who live on the territory of the Russian Federation are divided into two categories: dominant and small. Comparisons of First Nations with others possessing atomic weapons, for example, North Korea, are constantly being made. If the indigenous small peoples of the North, Siberia, and the Far East ceased to exist, Russia would not be able to preserve the territories of these regions. It is for this reason that the definition of "indigenous small peoples of the North, Siberia and the Far East" is proposed to be replaced in the legislation by a new definition: "native peoples of the North, Siberia and the Far East.

Everyone knows that the armed forces of the Russian Federation are powerful and reliable. The permafrost of the Far North is carefully protected by the brave ancestral peoples who live here. If the melting of ice in this region begins, it will be extremely difficult to ensure the preservation of the country's territory. To live in such extreme conditions all your life must have the strongest immunity. It was the original peoples of the North, constantly exposing their lives to risks, that managed to preserve permafrost. According to many politicians and scientists, IT technologies are the pinnacle of the development of civilization. In fact, having reached the peak of its development, man turns to the environment as the pinnacle of civilization of the whole world.

\footnotetext{
${ }^{\odot}$ Battakhov P.P., 2020
} 
When the USSR still existed, the northern peoples had large benefits, the state paid them various types of social assistance. Of course, now living conditions have changed significantly, but many residents could not get used to modern life, market relations. The North, Siberia, the Far East suffered from this, many residents lost their jobs and leave the northern regions to the central part of the country, but economic problems are not solved. Many residents of these regions do not work, and those who remained to work in their native lands have low wages. The young generation is increasingly striving to leave for settlements that are closer to the center of the Russian Federation in order to find work and decent living conditions. Gradually, residents cease to engage in such traditional activities as hunting, fishing, breeding deer and horse herds. Earlier, entrepreneurs were engaged in the sale of meat, and animal skins were handed over to enterprises where various products were made from them. However, today the law imposes many restrictions, which are much more than business permits[3].

In the territory of the Far North, where native peoples live, the state has an important task: to improve the quality of life of local residents, to ensure full employment. In recent years, the business sector has been developing slowly in the Far North, but innovations cannot be introduced, so they are postponed for an unknown time. Economic entities cannot operate due to various obstacles, one of which can be called too high taxation. The state needs to apply preferential taxation on this territory for subjects of traditional economic activity who are just starting their business. Traditionally, businessmen of the Far North are engaged in fishing, hunting, marine St. John's wort fishing, breeding deer and herds of the end, collecting wild plants, and engaged in craftsmanship. To stimulate the further development of the business sector in the Far North, it is necessary to solve 8 specific problems:

1. Support small businesses in the Far North. If a businessman decided to breed deer, a settlement of the market value of meat of this category in the market is required, because he will not be able to fully sell his products due to a very high price. It is important to subsidize fifty\% of products (on equal terms with the state and mining companies), which will make venison more accessible to consumers. So, the cost of a kilogram of meat should decrease by half and amount to 450 rubles. State support will stimulate entrepreneurs of the Far North to develop medium and small businesses here. A large number of poachers caused many problems in the field of fisheries. The need to pay taxes to the state becomes the reason that fishermen do not want to register their work as individual entrepreneurs, believing that this does not have economic benefits. Therefore, they continue to simply prey on fish, which is a violation of Russian law. Subsidizing fishermen by the state is necessary to eliminate such violations in the future.

2. To ensure the development of tourism in the Far North, because there are good places of rest for foreign tourists and citizens of Russia who love extreme. Local entrepreneurs can engage in the tourism business and attract new customers, because it is unlikely that anyone from the central region of the country will want to come here to work in the field of tourism. There is nothing surprising here, because only local residents will be able to cope with the harsh realities of the Far North;

- Living conditions are indeed extreme in harsh climates;

- The infrastructure is not developed;

- distance and difficulties with transport accessibility;

- The population of the territory is high.

Only local residents who know well the traditional way of life of this area will be able to conduct business in such conditions. But before starting to develop the tourism business in the Far North, it is necessary to ensure that there are qualified specialists who will be educated in the best Russian universities. Training is needed in tourism management, as well as in the economics of the tourism business.

3. Develop the development of IT technology, ensuring the development of mining companies that will extract cryptocurrency assets. The weather conditions of the Far North make it impossible to work on the street all year round. Here, winter lasts 9 months, and the remaining 
three months pass very quickly. For the opening of mining farms here are optimal conditions. In recent years, the younger generation has become increasingly interested in business in the IT sector, but many do not want to stay in the Far North and leave for the central regions of the Russian Federation or other countries. In fact, work in the field of IT technologies does not depend on weather conditions. In the Far North, it is necessary to create good business conditions so that this industry develops, because it has enormous advantages. In order for the business to develop, for novice entrepreneurs it is necessary to introduce a tax-free system of work for the first three years, then establish a tax of 3\%. In addition, support should be to lower the cost of electricity, because working in the IT sector requires significant energy costs. State support should be at least three years.

4. Providing financial support to novice businessmen of the Far North who want to engage in traditional activities for local places. For example, it can be the provision of loans in the amount of up to 3 million rubles on preferential terms. In addressing this issue, the issue of investment for the Arctic remains important [2]. The priority of financing for the state and local extractive companies should be social projects, including the construction of specialized institutions for children, sports facilities, multifunctional centers, transport and telecommunications systems. It is important to understand that in the Arctic zone the greatest wealth and value is the local population.

5. Provide professional training among the local population of the Far North, educate the younger generation in prestigious universities of Russia and other countries [2]. To encourage the younger generation to return to work in the Far North, provide them with an increased scholarship during the educational process, as well as mandatory employment after they receive a diploma. The graduate will have to work 5 years. Upon admission to the university in the target area, the extractive company fully reimburses the costs of training. After the training is completed, the company undertakes to ensure the employment of a graduate of the University, and he must reimburse the company for his training. For this, a certain time is worked out. Extractive companies, with the support of the state, need to provide graduates with targeted loans. All graduates of prestigious universities should be employed in the Far North[3].

6. The allocation of regional and municipal land territories to private ownership is an important issue of the market economy [4]. State-owned land should be supported by the authorities in the ownership of economic entities that breed horses and deer, which will be used for grazing. The State should provide financial support to local traditional reindeer and horse farms. In order to ensure the stable development of agriculture in the Far North, an increase in the number of horses and deer is required. The state is faced with the task of finding a distribution wound for products. For example, you can establish the export of horse and venison to other countries, as delicacies. As you know, it is the meat of such animals that has a beneficial effect on the human body, contributes to the cure of skin diseases, tuberculosis, typhoid fever, diathesis in children, etc.

Horse and deer breeding can develop, as a branch of management, only with the support of the state. It is for this reason that an appropriate environment must be created for this area of activity in the Far North. To date, the shortage of personnel is particularly acute in this area. In the territory of the Far North, these professions are in demand, but in universities there are no faculties that would give such knowledge. In this regard, it is necessary to develop and implement an education program that will allow the development of such important professions.

7. Improving living conditions and social benefits is the most pressing and pressing problem for First Nations. The social bloc of the country requires change. To improve the quality of life in the harsh regions of the Far North, it is necessary to provide local residents with housing that meets minimum standards, as well as full-fledged mobile communications.

8. Today, one of the areas of earnings of business entities is the transfer on a paid basis or the alienation of intellectual property and means of individualization, according to the commercial concession agreement, license agreement or on contractual grounds for the alienation of exclusive rights. To this end, it is extremely important to provide information and 
support to business entities when they undergo the registration of industrial property in Rospatent

In order for the state to solve all the above problems to support local businessmen in the Far North and ensure the employment of native residents, federal legislation requires some changes.

For example, I propose the following amendments to the first paragraph of article 24.1. FZ "On the development of small and medium-sized enterprises in the Russian Federation," namely to supplement it [5]:

a) the original peoples of the North, Siberia and the Far East.

The small or medium-sized business provides employment for citizens of certain categories, traditionally belonging to persons who require special social protection.

In accordance with the regulations of the Federal Law, economic entities will receive support from the state on an ongoing basis, residents will receive benefits at work places.

Today, the mining industry is actively developing in the Far North. However, small and medium-sized businesses here will be able to develop only with state support. It is possible to raise the country's economy only after the quality of life of the population has improved. Accordingly, innovative ideas are needed to develop business areas. It is for this reason that the younger generation should do business in the Far North in order to raise the quality of life in harsh conditions. A modern businessman is the engine for the development of the economic sphere and the entire humanity of the planet.

Thanks to the fact that the native people of the Far North managed to ensure the preservation of the large territory of the Far North and the Arctic, they will continue to ensure the preservation and development of the country's territory. It is the bravery of the ancestral peoples of the Far North that will ensure the territorial integrity and prosperity of the Russian Federation. To ensure the future socio-economic development of the Far North, the state needs to provide conditions for the development of small and medium-sized businesses in this region. The leadership of the Russian Federation needs to ensure the well-being of local residents. It is important to understand that the northern regions of the Russian Federation are special. Therefore, in order to regulate entrepreneurial relations, it is necessary to amend the Federal Law "On the Development of Small and Medium-Sized Enterprises in the Russian Federation."

When amending existing laws, it is necessary to supplement them in ways that will help fill the gaps in the legal regulation of entrepreneurial relations that exist between the economic entities of the region and the state.

Thus, when the proper legal regulation of business is ensured by the first peoples of the Far North, the Far East and Siberia, the economy of the Russian Federation will develop steadily.

\section{References:}

1. Collection of legislation of the Russian Federation, 24.04.2006, N 17 (2 h.), Art. 1905, Rossiyskaya Gazeta, N 86, 25.04.2006.

2. Battakhov Features of legal regulation of relations in the legal, economic and social spheres in the Arctic//Modern Science. 2020. № 6-1. C. 292-297.

3. Battakhov P.P. Legal regulation of entrepreneurial activities of the first peoples of the Far North, Siberia and the Far East//Economic research and development. 2020. № 8. S. 46-55.

4. Battakhov P.P. Certain problems of legal regulation in the Arctic territories//Modern Science. 2020. № 9-1. C. 133-139.

5. Battakhov P.P. Social entrepreneurship in Russia: some issues of legal regulation//" Issues of labor law "No. 6. C. 17-23. 